\title{
Blood pressure management in treatment-naïve hypertensive patients
}

\author{
Ji Yong Jung \\ Division of Nephrology, Department of Internal Medicine, Gachon University Gil Medical Center, Gachon University College of Medicine, \\ Incheon, Republic of Korea
}

\section{See Article on Page 31-42}

Hypertension is very common and can be asymptomatic or mild in the early stages, which can lead to various complications if not managed in a timely manner [1]. Many previous studies have reported that appropriate treatment of hypertension is beneficial to reduce the risk of negative cardiovascular disease (CVD) outcomes, including heart failure, stroke, myocardial infarction, and kidney failure [2]. For this reason, setting an optimal target blood pressure (BP) should be a primary concern. Although there can be inconsistencies among clinicians who treat patients with hypertension, the target BP is $140 / 90 \mathrm{mmHg}$ or lower, which has been the consensus for a long time [3]. However, based on recent studies that have indicated a lower target $\mathrm{BP}$ to be more effective, several guidelines have shown a preference to lower the traditional target BP. A large randomized controlled trial, the Systolic Blood Pressure Intervention Trial (SPRINT), showed that intensive control of systolic BP (SBP) at $<120 \mathrm{mmHg}$ reduced the risk of adverse clinical events [4]. Recently, different organization guidelines [5-7] have set the target BP somewhat lower (Table 1). However, since this target BP is a value measured by stan- dardized BP equipment, it tends to be difficult to apply in the outpatient clinic environment in Korea. Therefore, the Korean Society of Hypertension sets the target value somewhat higher in consideration of conventional BP measurement variations [8].

While strict BP control is clearly effective in reducing CVD risk and mortality, the risk of decreased kidney function due to renal hypoperfusion is important to consider when controlling hypertension [9]. Moreover, most previous trials have attempted to find an optimal target BP that can be used in patients prescribed antihypertensive drugs, so they cannot provide information on the appropriate timing of BP management in patients who have not been treated with antihypertensive drugs.

Lee et al. [10] analyzed 7,343 participants to investigate the association between BP and risk of incident chronic kidney disease (CKD) in a large prospective Korean population cohort who had never taken any prior antihypertensive medication. They used data from the Korean Genome and Epidemiology Study (KoGES) in which all participants underwent serial medical examinations (including biannual BP measurement); assessment of current antihypertensive and CVD medication use was based on participants' self-report questionnaires. The primary outcome was

Received: November 8, 2021; Revised: November 16, 2021; Accepted: November 16, 2021

Correspondence: Ji Yong Jung

Division of Nephrology, Department of Internal Medicine, Gachon University Gil Medical Center, Gachon University College of Medicine, 21 Namdong-daero 774 beon-gil, Namdong-gu, Incheon 21565, Republic of Korea. E-mail: jyjung@gachon.ac.kr

ORCID: https://orcid.org/0000-0003-1271-8012

Copyright (C) 2022 by The Korean Society of Nephrology

() This is an Open Access article distributed under the terms of the Creative Commons Attribution Non-Commercial and No Derivatives License (http:// creativecommons.org/licenses/by-nc-nd/4.0/) which permits unrestricted non-commercial use, distribution of the material without any modifications, and reproduction in any medium, provided the original works properly cited. 
Table 1. Target blood pressure recommendations for those with underlying comorbidities ( $\mathrm{mmHg}$ )

\begin{tabular}{|c|c|c|c|c|}
\hline Condition & $2018 \mathrm{KSH}$ & $2108 \mathrm{ESC} / \mathrm{ESH}$ & 2017 ACC/AHA & 2021 KDIGO \\
\hline \multirow[t]{2}{*}{ General } & $<140 / 90$ & $<140 / 90$ & $<130 / 80$ & \\
\hline & & $<130 / 80$ (tolerated) & & \\
\hline Elderly (age $\geq 65 \mathrm{yr}$ ) & $<140 / 90$ & $<140 / 80$ & $<130 / 80$ & \\
\hline Diabetes mellitus & & $<130 / 80$ & $<130 / 80$ & \\
\hline With CVD & $<140 / 85$ & & & \\
\hline Without CVD & $<130 / 80$ & & & \\
\hline CVD & & $<130 / 80$ & $<130 / 80$ & \\
\hline Cardiovascular & $\leq 130 / 80$ & & & \\
\hline Cerebrovascular & $<140 / 90$ & & & \\
\hline CKD & & $<140 / 80$ & $<130 / 80$ & $<120$ (SBP) (tolerated) \\
\hline No albuminuria & $<140 / 90$ & & & \\
\hline Albuminuria & $<130 / 80$ & & & \\
\hline
\end{tabular}

All targets were monitored optimally with standardized office blood pressure measurement equipment or automated oscillometric blood pressure monitoring.

ACC/AHA, American College of Cardiology/American Heart Association; CKD, chronic kidney disease; CVD, cardiovascular disease; ESC/ESH, European Society of Cardiology/European Society of Hypertension; KDIGO, Kidney Disease: Improving Global Outcomes; KSH, Korean Society of Hypertension.
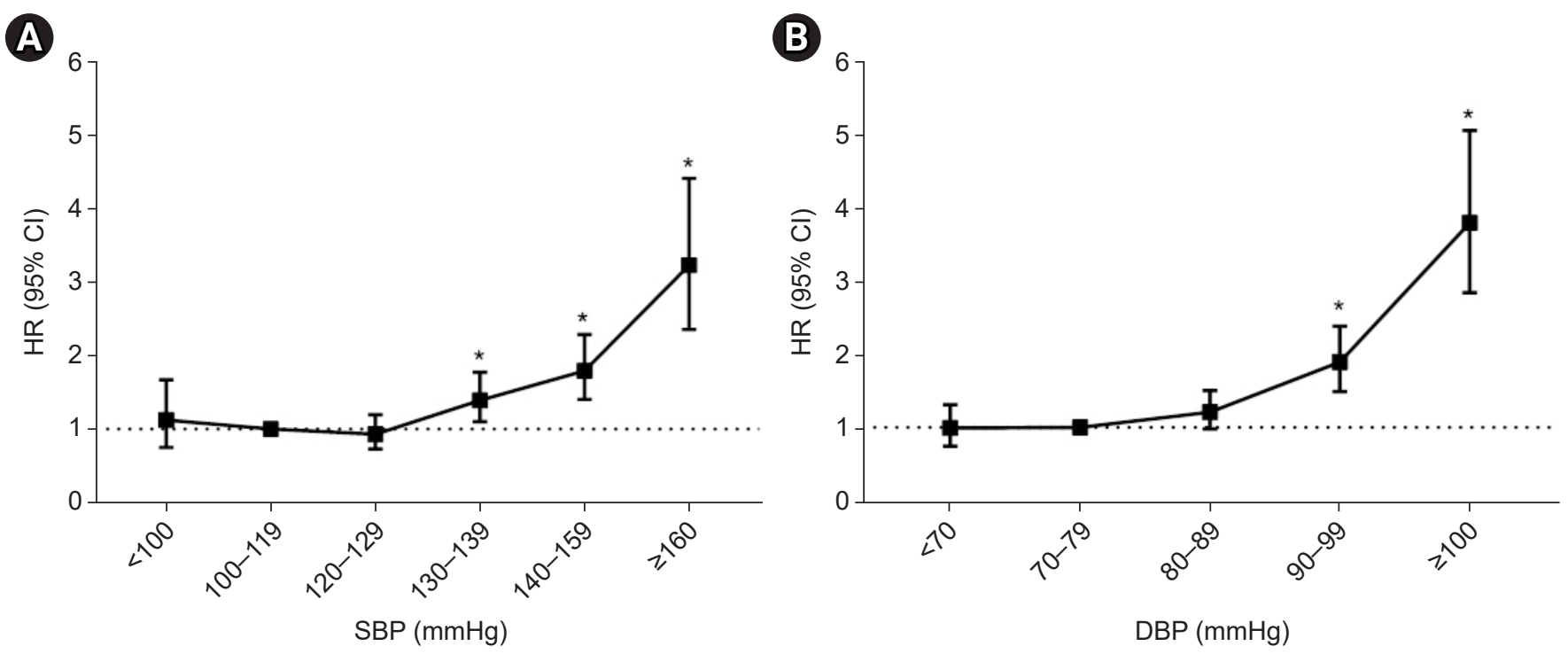

Figure 1. The relationship between blood pressure and incident chronic kidney disease in treatment-naive participants. An analysis of (A) systolic blood pressure (SBP) and (B) diastolic blood pressure (DBP) as time-varying variables led to creation of a reference group with SBP of 110-119 mmHg and DBP of 70-79 mmHg. The 95\% confidence interval (Cl) and hazard ratio (HR) for chronic kidney disease occurrence in each group was shown; ${ }^{*}<0.05$. This figure is based on the data in Table 1 of the original article [10].

incident CKD, and they also estimated incident CVD as a secondary outcome. The mean age of the participants was 51 years, and $51 \%$ of them were women. BP was measured five times on average during the follow-up period, and the mean SBP and diastolic BP (DBP) reading were 122 $\pm 17 \mathrm{mmHg}$ and $82 \pm 11 \mathrm{mmHg}$, respectively. Their study divided the participants into six categories according to SBP (<100, 100-119, 120-129, 130-139, 140-159, and $\geq 160$ $\mathrm{mmHg})$ and five categories according to DBP $(<70,70-79$,
80-89, 90-99, and $\geq 100 \mathrm{mmHg}$ ). When the BP was considered a time-varying variable, the risk of CKD was increased in patients with SBP of $\geq 130 \mathrm{mmHg}$ and DBP of $\geq 90 \mathrm{mmHg}$ (Fig. 1). The lowest CKD risk was identified in people with a time-varying SBP between 100 and $119 \mathrm{mmHg}$, and CKD hazard was nearly constant in those with time-varying DBP of $<80 \mathrm{mmHg}$. The incident CVD risk according to BP was similar to the incident CKD risk, as was observed in patients with SBP of $\geq 130 \mathrm{mmHg}$ and DBP of $\geq 90 \mathrm{mmHg}$. 
Although the authors used relatively large-scale prospective cohort data with well-managed data, there was a risk of selection bias because patients who were currently taking antihypertensive drugs and patients with a history of CKD and CVD were excluded at the start of the observation. In addition, although the researchers treated BP as a time-varying variable and analyzed it as such, it seems insufficient to represent patient BP data using BP measurements obtained only twice a year. After publication of the SPRINT trial results, there was a consensus on the tendency to decrease the optimal BP target. However, direct application of the results to treatment-naïve individuals requires caution because previous studies have targeted patients who are already taking antihypertensive drugs $[4,5,9]$. In this regard, the usefulness of this study [10] is to provide information that will help determine the timing of antihypertensive administration to treatment-naïve patients. However, because the target BP falls in the hypertension category, it is unclear why all patients are not prescribed antihypertensive agents. Therefore, it is not possible to provide information on the effectiveness of a therapeutic lifestyle; the only factors that can be assessed are the antihypertensive agent and the application period. In addition, the authors found an interaction between patient outcomes and age category through stratification analysis and reported that patients under 60 years of age with hypertension had increased risk of negative clinical outcomes. In addition to the low rates of awareness and treatment of hypertension, many elderly patients who had high risk of comorbidities were excluded at baseline, so a relatively good result could possibly have been obtained during the observation period.

In summary, Lee et al. [10] suggested that SBP of $\geq 130$ $\mathrm{mmHg}$ or DBP of $\geq 90 \mathrm{mmHg}$ was associated with an increased risk of incident CKD in hypertension treatment-naïve individuals. Therefore, while those BP readings are meaningful in suggesting the starting point of treatment to prevent the onset of CKD in this population, they do not provide an appropriate target during treatment. Thus, additional research is needed to determine the optimum BP for patients undergoing hypertension treatment.

\section{Conflicts of interest}

The author has no conflicts of interest to declare.

\section{ORCID}

Ji Yong Jung, https://orcid.org/0000-0003-1271-8012

\section{References}

1. Kearney PM, Whelton M, Reynolds K, Muntner P, Whelton PK, He J. Global burden of hypertension: analysis of worldwide data. Lancet 2005;365:217-223.

2. Hsu CY, McCulloch CE, Darbinian J, Go AS, Iribarren C. Elevated blood pressure and risk of end-stage renal disease in subjects without baseline kidney disease. Arch Intern Med 2005;165:923928.

3. Cruickshank JM, Thorp JM, Zacharias FJ. Benefits and potential harm of lowering high blood pressure. Lancet 1987;1:581-584.

4. SPRINT Research Group, Wright JT Jr, Williamson JD, et al. A randomized trial of intensive versus standard blood-pressure control. N Engl J Med 2015;373:2103-2116.

5. Whelton PK, Carey RM, Aronow WS, et al. 2017 ACC/AHA/ AAPA/ABC/ACPM/AGS/APhA/ASH/ASPC/NMA/PCNA Guideline for the Prevention, Detection, Evaluation, and Management of High Blood Pressure in Adults: a report of the American College of Cardiology/American Hear.

6. Williams B, Mancia G, Spiering W, et al. 2018 ESC/ESH Guidelines for the management of arterial hypertension. Eur Heart $J$ 2018;39:3021-3104.

7. Kidney Disease: Improving Global Outcomes (KDIGO) Blood Pressure Work Group. KDIGO 2021 Clinical Practice Guideline for the management of blood pressure in chronic kidney disease. Kidney Int 2021;99:S1-S87.

8. Lee HY, Shin J, Kim GH, et al. 2018 Korean Society of Hypertension Guidelines for the management of hypertension: part II-diagnosis and treatment of hypertension. Clin Hypertens 2019;25:20.

9. Beddhu S, Greene T, Boucher R, et al. Intensive systolic blood pressure control and incident chronic kidney disease in people with and without diabetes mellitus: secondary analyses of two randomised controlled trials. Lancet Diabetes Endocrinol 2018;6:555-563.

10. Lee H, Kwon SH, Jeon JS, Noh H, Han DC, Kim H. Association between blood pressure and the risk of chronic kidney disease in treatment-naïve hypertensive patients. Kidney Res Clin Pract 2022;41:31-42. 